NBER WORKING PAPER SERIES

\title{
SOURCES FOR FINANCING DOMESTIC CAPITAL - IS FOREIGN SAVING A VIABLE OPTION FOR DEVELOPING COUNTRIES?
}

\author{
Joshua Aizenman \\ Brian Pinto \\ Artur Radziwill \\ Working Paper 10624 \\ http://www.nber.org/papers/w10624 \\ NATIONAL BUREAU OF ECONOMIC RESEARCH \\ 1050 Massachusetts Avenue \\ Cambridge, MA 02138 \\ June 2004
}

Joshua Aizenman is Professor of Economics at the University of California, Santa Cruz. Brian Pinto is at the World Bank. Artur Radziwill is with the Center for Social and Economic Research (CASE), Warsaw, Poland. This paper is part of the on-going work on debt issues in Economic Policy Department of the Poverty Reduction and Economic Management Anchor at the World Bank. The views expressed herein are entirely those of the authors and do not necessarily represent the views of the World Bank, its Executive Directors or the countries they represent. We would like to thank Aart Kraay and Ashoka Mody for useful comments. Any errors are ours. The views expressed herein are those of the author(s) and not necessarily those of the National Bureau of Economic Research.

C2004 by Joshua Aizenman, Brian Pinto, and Artur Radziwill. All rights reserved. Short sections of text, not to exceed two paragraphs, may be quoted without explicit permission provided that full credit, including (C) notice, is given to the source. 
Sources for Financing Domestic Capital - Is Foreign Saving a Viable Option for Developing Countries?

Joshua Aizenman, Brian Pinto, and Artur Radziwill

NBER Working Paper No. 10624

June 2004

JEL No. F15, F21, F36, F43

\section{ABSTRACT}

This paper proposes a new method for measuring the degree to which the domestic capital stock is self-financed. The main idea is to use the national accounts to construct a self-financing ratio, indicating what would have been the autarky stock of tangible capital supported by actual past domestic saving, relative to the actual stock of capital. We use the constructed measure of selffinancing to evaluate the impact of the growing global financial integration on the sources of financing domestic capital stocks in developing countries. On average, $90 \%$ of the stock of capital in developing countries is self financed, and this fraction was surprisingly stable throughout the 1990s. The greater integration of financial markets has not changed the dispersion of self-financing rates, and the correlation between changes in de-facto financial integration and changes in selffinancing ratios is statistically insignificant. There is no evidence of any "growth bonus" associated with increasing the financing share of foreign savings. In fact, the evidence suggests the opposite: throughout the 1990s, countries with higher self-financing ratios grew significantly faster than countries with low self-financing ratios. This result persists even after controlling growth for the quality of institutions. We also find that higher volatility of the self-financing ratios is associated with lower growth rates, and that better institutions are associated with lower volatility of the selffinancing ratios. These findings are consistent with the notion that financial integration may have facilitated diversification of assets and liabilities, but failed to offer new net sources of financing capital in developing countries.

Joshua Aizenman

Department of Economics

1156 High Street

UCSC

Santa Cruz, CA 95060

and NBER

jaizen@ucsc.edu
Brian Pinto

MSN MC4-406

World Bank

1818 H Street, NW

Washington, DC 20433

bpinto2@worldbank.org
Artur Radziwill

Center for Social and Economic

Research

Sienkiewicza 12

00-944 Warsaw

Poland

artur.radziwill@case.com.pl 


\begin{abstract}
"For emerging markets, the consequence of these trends has been that they have rapidly become integrated into international capital markets. This has had a number of advantages. Private debt or portfolio inflows in response to economic liberalisation have expanded sizeably, from less than $\$ 40$ billion per year over the period 1983-1990, to an average of about $\$ 200$ billion a year in the last five years. These capital inflows have provided additional resources to supplement domestic savings and support high levels of investment."
\end{abstract}

-- Andrew Crockett, General Manager of the Bank for International Settlements, keynote address to the 33rd Seacen Governors' Conference in Bali on 13/2/98.

\begin{abstract}
"Neither a borrower nor a lender be, for loan oft loses both itself and friend, and borrowing dulls the edge of husbandry."
\end{abstract}

-- William Shakespeare, from Hamlet.

\title{
1. Introduction and summary
}

While capital account liberalization for developing countries may have been enthusiastically embraced at the beginning of the 1990s, it is safe to say that by the end of the decade, it had become the single most controversial policy prescription. Following the crises in East Asia and Russia, the debate shifted from when to liberalize the capital account to whether to liberalize it at all (e.g., Rodrik (1998)). John Williamson, the originator of the much-maligned term, "Washington Consensus", noted explicitly: "I specifically did not include comprehensive capital account liberalization, because that did not command a consensus in Washington." [Williamson (2002)]. These developments bear a sharp contrast to the early 1990s, when waves of market-oriented liberalization and greater financial liberalization fueled optimism about the growth prospects of developing countries. Economists expected growing financial integration to augment the capital stock in developing countries by making foreign saving available. This paper proposes a new and simple method for measuring the degree to which this expectation was fulfilled. The measure developed also provides useful information about the degree to which the domestic stock of capital is self-financed.

The seminal paper of Feldstein and Horioka (1980) focused on saving/investment correlations as a measure of capital mobility. It concluded that financial markets had a long way to go towards meaningful integration, even among advanced industrial countries. Their work sparked voluminous research, updating their study, and investigating the usefulness of S/I correlations in assessing the degree of integration of financial markets. Using saving/investment correlations, some concluded that financial markets have become more integrated in recent 
decades. Others concluded that such correlations do not provide enough information to ascertain the true degree of integration of financial markets [see Obstfeld and Rogoff (1999) and Coakleya, Kulasib and Smithc (1998) for useful overviews of the literature]. While the question addressed in this paper is akin to the one in Feldstein and Horioka (1980), we use a different methodology, focusing on the ratio of cumulative discounted gross national saving and gross national investment. This ratio provides us with a measure of self-financing - the share of domestic capital that was financed by domestic savings. We use this ratio to investigate the 1990s. The main results are:

I. We have not found evidence of a significant change in the pattern of financing ratios of developing countries in recent years. This is consistent with the notion that financial integration has facilitated greater diversification of assets and liabilities [see Dooley (1988) and Mody and Murshid. (2002) for analysis of this trend]. ${ }^{1}$ Frequently, greater financial integration has resulted in inflows of foreign saving financing outflows of domestic saving, with little net impact on financing ratios. One should note, however, that our paper is focusing on high level of aggregation. The relative stability of the self financing ratios documented in this paper is consistent with significant changes in the decomposition of the various forms of capital flows, as has been reported and analyzed by Bosworth and Collins (1999). ${ }^{2}$

II. The average self-financing ratio for developing countries is about $90 \%$ (i.e, on average, $90 \%$ of the stock of capital in developing countries is self-financed). This ratio remained stable throughout the 1990s notwithstanding the wave of financial liberalization - although there is significant heterogeneity, reviewed

\footnotetext{
${ }^{1}$ Mody and Murshid (2002) found in a sample of 60 developing countries that, while the growing financial integration with the rest of the world has increased access to foreign private capital, the relationship between foreign capital and domestic investment has weakened, reflecting changes in the composition of inflows, offsetting outflows, and increased foreign currency reserve requirements.

${ }^{2}$ Bosworth and Collins (1999) found that a substantial share of the surge in capital inflows has been channeled into reserves accumulation, and that an equal share found its way back out of the country. Using investment regressions, they found that FDI shows the strongest link with aggregate investment, with a coefficient close to one.
} 
later in this paper. Interestingly, the greater integration of financial markets has not changed the dispersion of self-financing rates, and the standard deviation of the cross-country distribution of self-financing ratios in the 1990s is about 0.18 .

III. There is no evidence of a "growth bonus" associated with increasing the financing share of foreign saving. The evidence suggests just the opposite: throughout the 1990s, countries with higher self-financing ratios grew significantly faster than countries with low self-financing ratios. This reinforces the skeptical assessment of the growth effects of financial liberalizations [see Rodrik (1998) and Gourinchas and Jeanne (2004); and Aizenman (2004) for a review of the debates about financial opening]. Yet, our results do not rule out the possibility that financial liberalization may impact the "quality of growth," as measured by TFP.

IV. Higher volatility of self-financing ratios, measured by the standard deviation of the ratio, is associated with lower growth rates. Better institutions are associated with a higher growth rate. Interestingly, in a growth regression, the quality of institutions variable "soaks" the explanatory power from the volatility of selffinancing ratios, rendering it insignificant, but leaving intact the positive convex effect of self-financing ratios on real per capita GDP growth.

Our analysis does not permit an inference about direct causality - we cannot infer that policies aimed at increasing self-financing ratios would be growth and welfare improving. All that we can infer is that despite greater financial integration, foreign savings on average have not provided a viable source of financing domestic capital for developing countries. The main benefit would seem to be greater financial asset diversification. Even on this account, the welfare effects are not clear-cut. Some studies suggest we have a long way to go before exhausting the bulk of the diversification gains [see Tesar (1999)]. Other studies suggest that the welfare effect of diversification is mixed in the presence of political polarization, where capital movements are motivated by the attempts to reduce the tax base available to future administrations [see Alesina and Tabellini (1989)]. 


\section{Methodology}

We use the national income accounts to construct a self-financing ratio, indicating what would have been the autarky stock of tangible capital supported by actual domestic past saving, relative to the actual stock of capital. Let gross investment and gross saving at time $t$, in constant PPP, be $I_{t} ; \quad S_{t}$, respectively. Let $k$ denote the fixed initial capital/GDP ratio, $d$ the depreciation rate, and $Y$ real GDP in constant prices. We define recursively the following stock variables, evaluated forward from time $t_{0}$ to time $t_{0}+n$ :

$$
K_{t_{0}}=k Y_{t_{0}} ; \quad K_{t+1}=K_{t}(1-d)+I_{t}, \quad \text { for } t_{0}+n \geq t>t_{0} .
$$

Similarly, we define recursively the "hypothetical autarky stock of capital," $\widetilde{K}$,

$$
\widetilde{K}_{t_{0}}=k Y_{t_{0}} ; \quad \widetilde{K}_{t+1}=\widetilde{K}_{t}(1-d)+S_{t} \quad \text { for } t_{0}+n \geq t>t_{0}
$$

The value of $\widetilde{K}_{t_{0}+n}$ is the "hypothetical autarky stock of capital" at time $t_{0}+n$, assuming the country would have self-financed its investment (and assuming that the path of the domestic saving would have been the one observed in the data, and a discounting horizon $n$ ).

The values $K_{t_{0}+n}$ and $\widetilde{K}_{t_{0}+n}$ rely on recursive discounting of $n$ periods, depending on the parameters $n, d$, and $k$, as well as on the accuracy of the GDP accounting data. If $n$ and $d$ are large enough, then $K_{t_{0}+n}$ and $\widetilde{K}_{t_{0}+n}$ would be insensitive with respect to the initial estimated stock of capital; and changing of the discounting horizon $n$ would lead to negligible changes of the estimated values. Henceforth we denote the estimated values of $K$ and $\widetilde{K}$ at time t, evaluated recursively use discounting horizon $n$, by

$$
\widetilde{K}_{t ; n}=\widetilde{K}_{t_{0}+n} ; K_{t ; n}=K_{t_{0}+n}
$$

The self-financing ratio at time $\mathrm{t}$, calculated using a horizon of $\mathrm{n}$ periods, is defined by: 
(3)

$$
f_{t ; n}=\frac{\widetilde{K}_{t ; n}}{K_{t ; n}}
$$

Applying (1) and (1'), the reduced form of (3) is

$$
f_{t ; n}=\frac{\sum_{i=1}^{n} S_{t-i}(1-d)^{i-1}+k Y_{t-n}(1-d)^{n}}{\sum_{i=1}^{n} I_{t-i}(1-d)^{i-1}+k Y_{t-n}(1-d)^{n}}
$$

In Appendix A we show that

$$
f_{t ; n}-f_{t-1 ; n} \cong \frac{S_{t-1}-I_{t-1}}{K_{t ; n}}-\left(f_{t-1 ; n}-1\right) \frac{d+g_{t}}{1+g_{t}}, \quad \text { where } g_{t}=\frac{K_{t ; n}}{K_{t-1 ; n}}-1 \text { is the growth rate of }
$$

the stock of capital at time t. Hence, current account surpluses exceeding

$$
\left(f_{t-1 ; n}-1\right) \frac{d+g_{t}}{1+g_{t}} \text { would increase the self-financing ratio. }{ }^{3}
$$

If $f$ were measured in ideal circumstances, a value of 1 would correspond to an economy where the entire stock of domestic capital is self-financed. A self-financing ratio below one indicates reliance on foreign saving -- $1-f$ is the foreign-financing ratio, measuring the fraction of domestic capital that was financed by foreign saving. Given the difficulty in measuring $f$ in practice, we shall focus more on its trend than whether it is above or below 1. To allow meaningful panel comparison across countries and across time we proceed by calculating the financing ratios of developing countries, varying $t$ but holding $n$ constant. Next, we evaluate the systematic changes of the distribution of the self-financing ratios in recent years. ${ }^{4}$ The choices of

\footnotetext{
${ }^{3}$ A natural benchmark is financial autarky $(f=1)$, where the entire domestic stock of capital is self financed. A balanced current account $(\mathrm{S}=\mathrm{I})$ would preserve the financial autarky position of the economy. In contract, a country that over-finance its stock of capital $(f>1$, like the position of Japan in the eighties), would find that maintaining a stable self-financing ratio overtime requires running a current account surplus proportional to the over-financing rate $(f-1)$ times the sum of the growth rate and the depreciation rate. For such a country, a balanced current account position would reduce the self financing ratio overtime, towards $f=1$.

${ }^{4}$ We use data for 47 developing and 22 high incem OECD countries that are available for every year between 1981 and 2001 from the 2004 World Development Indicators database. Variables GDP, gross national savings (including
} 
$n$ and $d$ are dictated by data availability and the desire to have a large enough sample of developing countries. In the base specification, we set $\mathrm{k}=3, \mathrm{n}=10$ and $d=0.1$, ending with a panel of self-finance ratios covering the 1990s for 47 countries. ${ }^{5}$ As we do not have any obvious benchmark year to anchor the calculations of the self-financing ratios for all countries, we impose a fixed discounting horizon $n$ for all countries. In Appendix A we show that an exact version of (5) applies if the calculations of the self-financing ratios are anchored at fixed base year $t_{0}$ (thereby implying a time dependent discounting horizon, of $t-t_{0}$ ). For large enough $\mathrm{n}$ and $\mathrm{d}$, the difference between the two possible ways is of a second order magnitude. In the Appendix we also characterize the difference between the self-finance measure (4), and the 'ideal' selffinance measure, denoted by $\hat{f}$. This ideal measure would be obtained by unbounded backward discounting, had we have all the past information. The Appendix shows that for an economy growing at a constant rate $g$,

$$
f_{t ; n}-\hat{f}_{t}=\left(1-f_{t ; n}\right) \frac{[(1-d) /(1+g)]^{n}}{1-[(1-d) /(1+g)]^{n}} .
$$

Consequently, for large $n$ and $d$, the gap between (4) and the ideal self-financing measure is inconsequential.

It is useful to note that the self-financing ratio defined in (3) provides information that differs from the calculations of country portfolios [see Kraay et. al. (2000)] and external wealth of nations [see Lane and Milesi-Ferretti (2001)]. These papers evaluate the net assets and characterize the portfolios of a country, hence rely on current market prices of assets and liabilities. In contrast, the self-financing ratio identifies the degree to which the stock of capital has been self-financed, aggregating past gross domestic saving and investment. While valuation changes (due to real exchange rate shocks, stock market changes, partial defaults, etc.) would have first-order effects on the wealth and net worth of nations, these would have only secondorder impacts on the self-financing ratios.

Before turning to the main results, we would like to acknowledge the obvious limitations of our methodology. First, the quality of the self-financing ratios evaluated in this study is

net current transfers from abroad) and gross fixed capital formation are expressed in constant local currency units. GDP per capita is expressed in constant 1995 US\$.

${ }^{5}$ The choice of the depreciation rate follows Nadiri and Prucha (1996), estimating the deprecation rates of various types of capital in the range of 0.06-0.12. 
limited by the quality and availability of the data, and the accuracy of the assumptions about the various parameters $[k, d$, etc.]. Second, the skepticism in the literature about the interpretation of the Feldstein and Horioka correlations applies to this paper as well, as we do not attempt to model the forces leading to the observed financing ratios. With these caveats, we argue that sharp changes in self-financing ratios, or the absence of such changes, provide useful diagnostic information about structural changes associated with the integration of capital markets.

\section{Self-financing ratios of developing countries in the $1990 \mathrm{~s}$}

The analysis begins by evaluating the patterns of self-financing ratios throughout the 1990s. For data limitation reasons, we choose $n=10$ [recall that $\mathrm{n}$ is the window of calculating the financing share, see (1) and ( $\left.\left.1^{\prime}\right)\right]$, and a depreciation rate $d=0.1$. The basic patterns of selffinancing ratios for developing countries in the 1990s are depicted in Figure 1.A. The mean financing ratio hovers about 0.9 , with no obvious trend ${ }^{6}$. Interestingly, despite the wave of financial liberalizations, there is no detectable increase in the spread of the financing ratios, as measured by one standard deviation around the mean. Disaggregating across regions in Figures 1.B-1.D reveals considerable heterogeneity. First, only in Latin America does there seem to be a weak trend towards greater dispersion of the financing ratio, with a marginal decline of the mean from about 0.9 to 0.87 . The opposite is observed in Asia: the self-financing ratio increased from 1.01 to 1.06 , and the dispersion declined. Most of the increase is observed in the aftermath of the 1997-8 crisis. However, the trend in Africa resembles that in Latin America, dropping from 0.87 to 0.83 , but with a significant drop in dispersion. These figures are consistent with the notion that, as a region, Asia has financed domestically its rapid accumulation of capital, and the 1997-8 crisis has led to a significant surge in precautionary saving. In contrast, Latin America and Africa have increased their reliance on foreign savings as means of financing their tangible capital, by about $3 \%$. As the counterpart to self-financing dynamics in developing countries, we observe the increase in mean and standard deviation of self-financing ratios among OECD countries (Figure 1.E). However, the increase in the mean self-financing ratio from 0.98 to 1.04

\footnotetext{
${ }^{6}$ These figures depict arithmetic averages. Weighting would lead to much higher ratios, reflecting high selffinancing ratios in the most populous countries, including China.
} 
overstates the increase in amount of saving available to the developing countries, as ratios in major economies such as USA, Japan and Germany remained remarkably stable ${ }^{7}$.

We now examine the association between real per capita GDP growth and the level and volatility of self-financing ratios in the 1990s. Table 1 summarizes the cross country regressions of the average real per capita GDP growth rate in the 1990s on the average self-financing ratio, on the square and the cube of the financing gap, $f-1$, and on the volatility of the self-financing ratio. Column 1 presents results without controlling for quality of institutions and measures of trade and financial openness. On balance, higher self-financing ratios (implying higher self financing of a given investment) are associated with a significant increase in growth rates. This effect is convex, as shown in Figure 2, which plots the relationship between the self-financing ratio and per capita GDP growth rates for the case of a stable self-financing ratio. A rise in the self-financing ratio from 1 to 1.1 is associated with an increase in the growth rate from $2.8 \%$ to 4.4\%. Further, reducing the self-financing ratio from 1 to 0.9 is associated with a drop in the growth rate from $2.8 \%$ to $2.2 \%$. Regarding volatility, column 1 indicates that increasing the s.d. of the self-financing ratio from zero to 0.05 would reduce the growth rate associated with a given average self-financing rate by almost $1 \%$ !

Table 2 shows that better institutions are associated with less volatile self-financing ratios, which suggests that the adverse effects of higher volatility of self-financing ratios on growth may stem from institutional weaknesses. This conjecture is confirmed in column 2 of Table 1, which repeats the regression reported in column 1 while controlling for the quality of institutions. Better institutions are associated with a higher growth rate. Interestingly, the quality of institutions variable "soaks" the explanatory power from the volatility of self-financing ratios, rendering it insignificant, but leaving intact the positive convex effect of self-financing ratios on real per capita GDP growth. Results from Table 2 indicate further that trade openness, unlike financial openness tends to be positively associated with standard deviation in selffinancing ratios ${ }^{8}$.

\footnotetext{
${ }^{7}$ After the mild increase in first half of 90s US self-financing ratio was actually falling in the aftermath of series of financial crises in emerging markets in 1997 and 1998, so that in 2001 it equaled 0.94 compared to 0.95 in 1991. Self-financing ratio in Japan and Germany remained flat at 1.06 and 0.97 , respectively.

${ }^{8}$ The quality of institutions was calculated as the average of measures of law and order, corruption and bureaucracy quality from the International Country Risk Guide (2004). The data on trade openness - measured by [exports +
} 
Finally, cross-country differences in levels and changed of self-financing ratios cannot be explained by variables such as quality of institutions, trade and financial openness 9 . Notably the correlation between the change in de-facto financial openness between 1980s and 1990s and the change in the self-financing ratio between 1991 (result of accumulation in decade of 1980s) and 2001 (accumulation in 1990s) is, for all practical purposes, zero (compare Figure 3). Also, while the financial opening was substantial - the average and median increases in financial openness were $65 \%$, and $30 \%$, respectively, changes in the self- financing rates were comparably insignificant $^{10}$.

\section{Self-financing ratios - regional and selected countries' experience}

Figures 4-5 report the time patterns of the self-financing ratios, and the corresponding growth rates, in the three blocks of developing countries [Latin America, Asia and Africa]. Throughout the nineties, Asia exhibits high self-financing ratios and high growth rates (with the exception of 1998). In contrast, Latin America and Africa display low self-financing ratios, and relatively low growth rates. Interestingly, the drop in the self-financing ratios in Africa through much of the 1990s was not associated with a sustained growth bonus - the growth rate picked up in the early 1990s, collapsing in the second half. The growth performance of Latin America was more evenly distributed throughout the nineties, exhibiting no obvious growth bonus of the drop in the self-financing rations. Unlike the experience of Africa, the growth drop of Asia in the aftermath of the $1997-8$ crises had been associated with a remarkable increase of the selffinancing ratios.

We now briefly review the patterns of self-financing ratios and growth of selected countries. Figures 6.A and 6.C pertain to the two most populous countries, China and India. Both experience rapid self-financed growth --their self-financing 1990s ratios are greater than

imports]/GDP and financial openness--measured by [inflows + outflows of capital]/GDP--are from Frankel and Wei (2004).

${ }^{9}$ These econometric results are not shown here but are available upon request.

${ }^{10}$ Financial openness actually fell between the 80 s and the $90 \mathrm{~s}$ in number of countries, including Ecuador, Uruguay, Bangladesh, Egypt and Morocco. Another outlier in the Figure 3 is Mozambique that doubled its self-financing ratio since 1991 (but the ratio is still very low at 0.43 in 2001). 
one. The main difference is that the self-financing ratio exhibits rapid downward trend in China, and very mild upward trend in India. There results are in line with the cross country regression reported in Table 1, which details the positive association between self-financing ratios and growth. To complete this picture, figure 6.B focuses on Brazil, a country that experienced even more rapid decline self-financing ratio as China from lower initial level. Characteristically, the country failed to benefit from any associated "growth bonus". This is a pattern common to the "average" Latin American country [see Figures 3 and 4]. Another characteristic case is Bolivia depicted in Figure 6.D, the country that is characterized by exceptionally low levels of selffinancing ratios, but also mediocre growth performance.

While countries characterized by higher self-financing ratio in 1990s experienced, on average, higher growth rates, there are several examples of countries that experienced large increase in self-financing ratios, with no detectable growth bonus. Figure 6.E and 6.F reports the experience of Ecuador and Pakistan -- the self-financing ratios of both countries increased substantially in the 1990s, at a time when their growth rates were rather flat (Ecuador) or dropped substantially (Pakistan). Thus, there is no guarantee that a rising self-financing ratio will produce faster growth ${ }^{11}$. Economic growth depends on all the factors that explain the magnitude and the quality of investment in all types of capital. For most developing countries, the obstacles preventing higher growth are not the degree of financial integration, but other more structural obstacles.

Figure 7 focuses on special category of countries, those that experienced serious financial crisis and associated sudden stop in external financing. All these countries, with exception for Indonesia, are characterized by the reversal of declining self-financing ratios around the time of the crisis episode. Interestingly, the harshness of the reversal varies greatly among countries.

Figure 7.A summarizes the experience of Korea. Similar to China, throughout the 1990s the relatively high growth rate of Korea was, on balance, self-financed. Yet, the Korean pattern is dominated by the financial liberalization in the mid 1990s, and the sudden stop of 1997-8. While the financial liberalization of the mid 1990s is associated with a sizable drop in the self financing ratio, the sudden stop, and remarkable adjustment that followed, have led to a sharp

\footnotetext{
${ }^{11}$ For example, if a country has unsustainable public debt dynamics and cuts back fiscal spending (including public investment), then this will tend to raise national savings relative to investment, raising the self-financing ratio at the margin; but possibly with a growth slowdown because of the necessary reduction in aggregate demand.
} 
reversal of the self-financing ratio. Yet, the self-financing rate in 2001 (marginally above 1), was well below the self-financing rate observed in 1991 (about 1.035). Figures 7.C and 7.D report the growth and self-financing ratios of Malaysia and the Philippines, respectively. The patterns of both countries resemble that of Korea, however an increase in the self-financing ratios in the aftermath of the 1997-8 crisis was much sharper. This can be explained by the fact that pre-crisis self-financing ratios in these countries were substantially lower and falling below 0.9 shortly before the episode while in the aftermath of crisis, countries returned to full selffinancing. This is consistent with the observation that the East Asia crisis led the affected countries to follow a similar pattern -- a sizeable increase in precautionary savings, quite independently of their de-jure integration with the global financial system. Indeed, this pattern is exhibited by the regional means and standard deviation of self-financing ratio in Figure 1.C.

Figure 7.E deals with the dramatic experience of Argentina. The financial opening of the $1990 \mathrm{~s}$ is associated with a sizable drop in the self-financing ratio, from about 0.92 to 0.88 . This drop ends with the sudden stop, which led to a partial reversal of the earlier decline. As in the previous cases, the ability to finance a growing share of the domestic capital by foreign saving is not associated with any "growth bonus." In fact, the period of relatively rapid growth in the early 1990s is associated with a higher self-financing ratio. Mexico, depicted in Figure 7.F, exhibits the crisis triggered reversal in self-financing ratio decline, with economic growth that is on average stronger during the time of increasing self-financing ratio. These results suggest that political economy factors and political risk diversification are important in understanding the association between the self-financing ratios and growth. ${ }^{12}$

\footnotetext{
${ }^{12}$ For example, for countries characterized by economic and political uncertainty, the opening of financial markets would lead domestic agents to put greater share of their savings in offshore accounts, and in certain cases may lead foreign consumers to purchase domestic assets, betting on the prospect of improvement in domestic conditions. This may lead to large gross flows of capital, with little change in net flows [see Dooley (1998)].
} 


\section{Concluding remarks}

Our study proposes a new method for evaluating the net sources for financing the domestic stock of capital. We illustrated the usefulness of this method by evaluating the actual patterns of financing the capital stock of developing countries in the 1990s. Combining this method with measures of de-facto financial integration enables one to trace the association between gross and net capital flows. Among our results, we find that throughout the 1990s, a period characterized by a rapid increase in gross capital flows, developing countries exhibit stable self-financing ratios. As is frequently the case, the quality of the results is limited by the quality of the data, and the auxiliary assumptions. For some countries, the calculated self-financing ratio may underestimate the actual. ${ }^{13}$ Tracing these biases is left for future investigation. While the exact results of the self-financing ratios are sensitive to these considerations, we expect the main findings to be robust.

\footnotetext{
${ }^{13}$ For example, if the trade data were distorted due to illicit capital flight intermediated via trade mis-invoicing, and if illicit capital flight exceeded illicit capital inflows, the actual gross saving would tend to exceed the one traced by our calculations. See Aizenman and Noy (2004) for further discussion of trade mis-invoicing and endogenous defacto financial openness.
} 


\section{References}

Aizenman, J. (2004) "Financial Opening: Evidence and Policy Options," in "Challenges to Globalization", R. Baldwin and A. Winters, eds., University of Chicago Press, 2004.

I. Noy I. (2004) "Endogenous Financial and Trade Openness: Efficiency and Political Economy Considerations", manuscript, UCSC.

Alesina, A. and Tabellini, G. (1989) "External Debt, Capital Flight and Political Risk," Journal of International Economics, vol. 27, pp.199-220.

Bosworth B. P. and Collins, S. M. (1999) "Capital Flows to Developing Economies: Implications for Saving and Investment," Brookings Papers on Economic Activity:1, Brookings Institution, pp. 143-69.

Coakleya, J., Kulasib F. and Smithc R. (1998) “The Feldstein-Horioka Puzzle and Capital Mobility: A Review," International Journal of Finance and Economics 3: 169-188.

Dooley, M. (1988) "Capital Flight: A Response to Differences in Financial Risks," IMF Staff Papers, September 1988.

Feldstein, M. \& Horioka, C. (1980) "Domestic Saving and International Capital Flows". The Economic Journal, 90, 358, 314-329.

Frankel, J. and Wei S. (2004) "Managing Macroeconomic Crises: Policy Lessons", forthcoming as Chapter 7 in Economic Volatility and Crises: A Policy-Oriented Guide, Aizenman J. and B. Pinto (eds.), World Bank, Washington DC.

Gourinchas P. O. and Jeanne O. (2004) “The Elusive Gains from International Financial Integration," IMF WP/04/74.

Kraay A, Loayza, N., Serven, L. and Ventura J. (2000) “Country Portfolios,” NBER Working Paper 7795.

Lane, P. and Milesi-Ferretti G. M. (2001) "The external wealth of nations: Measures of Foreign Assets and Liabilities For Industrial and Developing Countries," manuscript.

Mody, A. and Murshid. A. P. (2002) “Growing Up With Capital Flows,” IMF Working Paper $\mathrm{WP} / 02 / 75$.

Nadiri, M. I. and Prucha I. R. (1996) "Estimation of the Depreciation Rate of Physical and R\&D Capital in the U.S. Total Manufacturing Sector" Economic Inquiry, vol. xxxiv, no. 1, p. 43-56, January 1996. 
Obstfeld, M. and Rogoff K. (1999) “International Macroeconomics,” MIT Press.

Rodrik, D. (1998) “Who Needs Capital-Account Convertibility?” in Peter Kenen (ed), Should the IMF Pursue Capital Account Convertibility? Essays in International Finance no. 207, Princeton: Princeton University Press (May).

Tesar, L. (1999) “The Role of Equity in International Capital Flow,” in M. Feldstein (ed). International Capital Flows, University of Chicago Press.

Williamson, J. 2002 "Did the Washington Consensus Fail?" Outline of remarks at the Center for Strategic \& International Studies, November

6.http://www.iie.com/publications/papers/williamson1102.htm 


\section{Appendix}

The purpose of this appendix is to characterize the factors explaining the evolution of self-financing ratios overtime, and to compare the self financing ratios associated with fixed versus variable discounting horizon.

Equations (1)-(4) correspond to the case of a fixed discounting horizon, $n$. The dynamics of the self-financing ratios are summarized by the following :

Claim: $\quad f_{t ; n}-f_{t-1 ; n} \cong \frac{S_{t-1}-I_{t-1}}{K_{t ; n}}-\left(f_{t-1 ; n}-1\right) \frac{d+g_{t}}{1+g_{t}}, \quad$ where $g_{t}=\frac{K_{t ; n}}{K_{t-1 ; n}}-1$ is the growth rate of the stock of capital at time t.

Applying (1) and (1'),

$$
\begin{aligned}
\widetilde{K}_{t ; n} & =\sum_{i=1}^{n} S_{t-i}(1-d)^{i-1}+k Y_{t-n}(1-d)^{n} \\
K_{t ; n} & =\sum_{i=1}^{n} I_{t-i}(1-d)^{i-1}+k Y_{t-n}(1-d)^{n}
\end{aligned}
$$

Hence

(A3)

$$
\begin{gathered}
f_{t ; n}-1=\frac{\sum_{i=1}^{n}\left[S_{t-i}-I_{t-i}\right](1-d)^{i-1}}{K_{t ; n}}= \\
\frac{(1-d) \sum_{i=1}^{n}\left[S_{t-1-i}-I_{t-1-i}\right](1-d)^{i-1}+S_{t-1}-I_{t-1}-\left[S_{t-1-n}-I_{t-1-n}\right](1-d)^{n}}{K_{t ; n}}=
\end{gathered}
$$

$$
\begin{aligned}
& \frac{S_{t-1}-I_{t-1}-\left[S_{t-1-n}-I_{t-1-n}\right](1-d)^{n}}{K_{t ; n}}+(1-d) \frac{\sum_{i=1}^{n}\left[S_{t-1-i}-I_{t-1-i}\right](1-d)^{i-1}}{K_{t-1 ; n}} \frac{K_{t-1 ; n}}{K_{t ; n}} \cong \\
& \frac{S_{t-1}-I_{t-1}}{K_{t ; n}}+\left(f_{t-1 ; n}-1\right) \frac{1-d}{1+g_{t}}
\end{aligned}
$$

where $g_{t}=\frac{K_{t ; n}}{K_{t-1 ; n}}-1$ is the growth rate of the stock of capital at time t, and we assumed that $(1-d)^{n}$ is small, such that we can neglect the impact of $\frac{\left[S_{t-1-n}-I_{t-1-n}\right](1-d)^{n}}{K_{t ; n}}$.

Consequently,

$$
f_{t ; n}-f_{t-1 ; n} \cong \frac{S_{t-1}-I_{t-1}}{K_{t ; n}}-\left(f_{t-1 ; n}-1\right) \frac{d+g_{t}}{1+g_{t}}
$$


Had we used a fixed point in time for the base year, say $t_{0}$, than the discounting horizon used to evaluated the self financing ratio at time $t$ would have been $m=t-t_{0}$, increasing each period by one period. It is easy to verify that in this case,

$$
\begin{aligned}
\widetilde{K}_{t} & =\widetilde{K}_{t-1}(1-d)+S_{t-1} \\
K_{t} & =K_{t-1}(1-d)+I_{t-1}
\end{aligned}
$$

A modified version of (A4) will hold. The main difference between the cases of fixed versus moving discounting horizon is that equation (A4) is an approximation, whereas (A4') holds as a precise equality

(A4')

$$
\begin{aligned}
& f_{t}-1=\frac{\sum_{i=1}^{m}\left[S_{t-i}-I_{t-i}\right](1-d)^{i-1}}{K_{t}}=\frac{(1-d) \sum_{i=1}^{m-1}\left[S_{t-1-i}-I_{t-1-i}\right](1-d)^{i-1}+S_{t-1}-I_{t-1}}{K_{t}}= \\
& \frac{S_{t-1}-I_{t-1}}{K_{t}}+(1-d) \frac{\sum_{i=1}^{m-1}\left[S_{t-1-i}-I_{t-1-i}\right](1-d)^{i-1}}{K_{t-1}} \frac{K_{t-1}}{K_{t}}=\frac{S_{t-1}-I_{t-1}}{K_{t}}+\left(f_{t-1}-1\right) \frac{1-d}{1+g_{t}}
\end{aligned}
$$

The difference of the time evolutions of two alternative self-financing ratios has the order of magnitude of

$\frac{\left[S_{t-1-n}-I_{t-1-n}\right](1-d)^{n}}{K_{t ; n}}$. For large enough $d$ and $n$, the difference is of a second order magnitude. An advantage of the fixed discounting horizon $\mathrm{n}$ is that it should allow better comparison across time, especially for the case of different base years applied to various countries.

\section{The bias associated with fixed discounting horizon:}

Our empirical analysis was based on a fixed discounting horizon, n, assuming that the initial stock of capital $\left(K_{t-n}\right)$ was self financed. We evaluate now the magnitude of the bias introduced by this assumption. For simplicity of exposition, we focus on the case where the real GDP, real saving and real investment grow at a constant rate, $\mathrm{g}$, and each period a constant fraction of the investment is self-financed. Hence, $I_{j}=I_{j-1}(1+g) ; \quad S_{j}=S_{j-1}(1+g)$. We denote the 'ideal' self-financing ratio by $\hat{f}$. This 'ideal' measure is obtained by unbounded backward discounting -- 
(A6) $\hat{f}_{t}=\frac{\sum_{i=1}^{\infty} S_{t-i}(1-d)^{i-1}}{\sum_{i=1}^{\infty} I_{t-i}(1-d)^{i-1}}=\frac{\sum_{i=1}^{\infty} S_{t-1}\left[\frac{1-d}{1+g}\right]^{i-1}}{\sum_{i=1}^{n} I_{t-1}\left[\frac{1-d}{1+g}\right]^{i-1}}=\frac{S_{t-1} \frac{1-Q^{n}}{1-Q}+S_{t-1} \frac{Q^{n}}{1-Q}}{I_{t-1} \frac{1}{1-Q}}$, where $Q=\frac{1-d}{1+g}$.

In contrast, the estimated self-financing ratio is

$$
f_{t ; n}=\frac{\sum_{i=1}^{n} S_{t-i}(1-d)^{i-1}+k Y_{t-n}(1-d)^{n}}{\sum_{i=1}^{n} I_{t-i}(1-d)^{i-1}+k Y_{t-n}(1-d)^{n}}=\frac{\sum_{i=1}^{n} S_{t-1} Q^{i-1}+k Y_{t-n}(1-d)^{n}}{\sum_{i=1}^{n} I_{t-i} Q^{i-1}+k Y_{t-n}(1-d)^{n}}=
$$

$$
\frac{S_{t-1} \frac{1-Q^{n}}{1-Q}+k Y_{t-n}(1-d)^{n}}{I_{t-1} \frac{1-Q^{n}}{1-Q}+k Y_{t-n}(1-d)^{n}}
$$

The actual stock of capital is obtained by the backward discounting of all past investment:

$$
k Y_{t-n}=K_{t-n}=\sum_{i=1}^{\infty} I_{t-n-1}\left(\frac{1-d}{1+g}\right)^{i-1}=\frac{I_{t-n-1}}{1-Q}=\frac{I_{t-1}(1+g)^{-n}}{1-Q} .
$$

Applying (A8) to (A7), collecting terms, we infer

$$
f_{t ; n}=\frac{S_{t-1} \frac{1-Q^{n}}{1-Q}+I_{t-1} \frac{Q^{n}}{1-Q}}{I_{t-1} \frac{1}{1-Q}} .
$$

Subtracting (A9) and (A6) we infer that

$$
f_{t ; n}-\hat{f}_{t}=\frac{I_{t-1} \frac{Q^{n}}{1-Q}-S_{t-1} \frac{Q^{n}}{1-Q}}{I_{t-1} \frac{1}{1-Q}}=\frac{I_{t-1} \frac{Q^{n}}{1-Q}-\hat{f}_{t} I_{t-1} \frac{Q^{n}}{1-Q}}{I_{t-1} \frac{1}{1-Q}}=\left(1-\hat{f}_{t}\right) Q^{n}
$$

Alternatively,

$$
\text { (A11') } f_{t ; n}-\hat{f}_{t}=\left(1-\hat{f}_{t}\right) Q^{n}=\left(1-f_{t ; n}+f_{t ; n}-\hat{f}_{t}\right) Q^{n} .
$$

Hence,

$$
f_{t ; n}-\hat{f}_{t}=\left(1-f_{t ; n}\right) \frac{Q^{n}}{1-Q^{n}}
$$


Truncating the discounting horizon to $\mathrm{n}$ periods biases the self-financing ratio. The bias equals $1-\hat{f}$, times $[(1-d) /(1+g)]^{n} \cdot{ }^{14}$ For large enough $d, g$ and $n$, the resultant bias is inconsequential. For example, for $n=10, d$ $=0.1, g=0.03$, and $f=0.9$, the estimated self financing ratio exceeds the 'ideal' one by 0.035 . A higher growth rate reduces the bias. Had the growth rate been $g=0.06$, the bias $f-\hat{f}$ would drop to 0.025 . An implication of the above discussion is that applying fixed discounting horizon (n) prevents spurious dynamics in the self financing ratio, by keeping the bias constant overtime. ${ }^{15}$

14 The bias identified above applies for the full information case. Uncertainty may introduce another bias, stemming from the possibility that the initial stock of capital is imprecisely estimated. Unlike the bias identified in (A12), some of the uncertainty biases may be independent from the discounting horizon, $\mathrm{n}$.

${ }^{15} \mathrm{Had}$ we used a fixed point in time for the base year, say $t_{0}$, then the discounting horizon used to evaluated the self financing ratio at time $t$ would have been $m=t-t_{0}$, increasing each period by one period. This is equivalent to increasing the effective $\mathrm{n}$ over time, reducing thereby the bias calculated in (A12). 


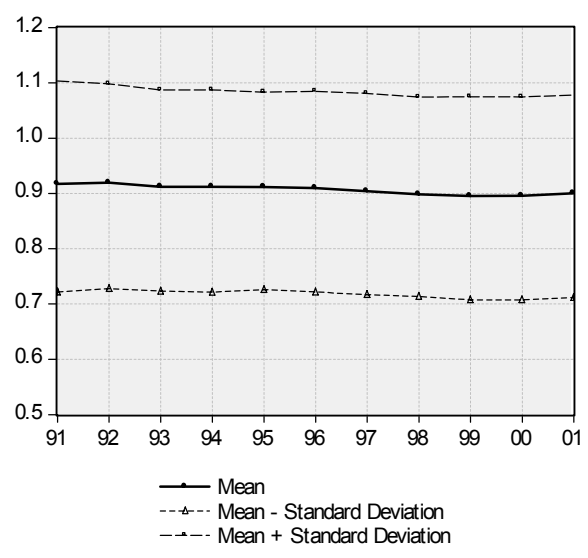

1.A

All Developing Countries

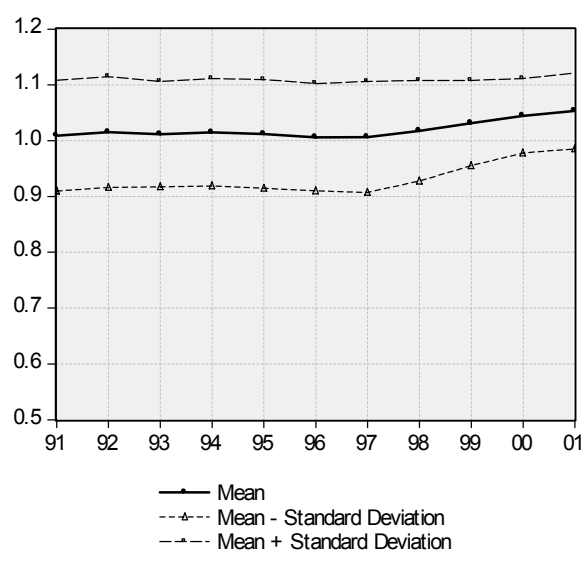

1.C

Asian Countries

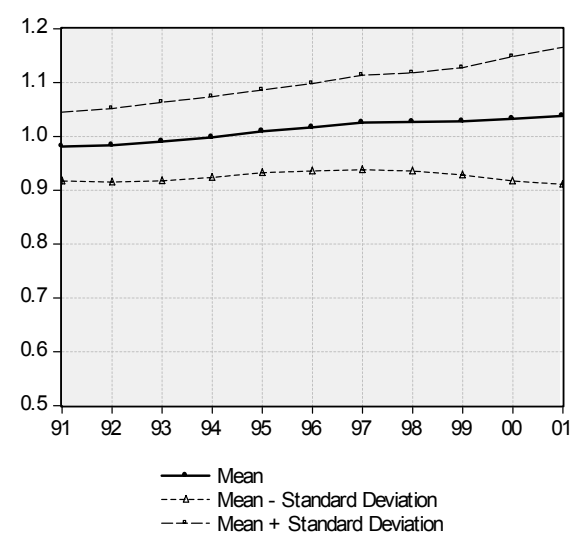

1.E

High Income OECD countries

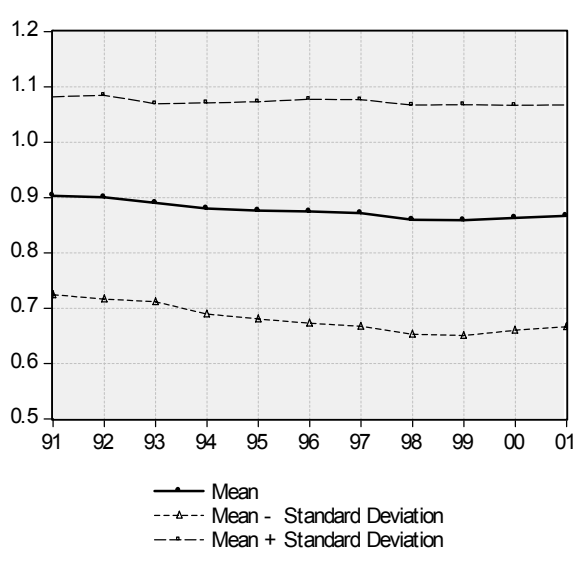

1.B

Latin American Countries

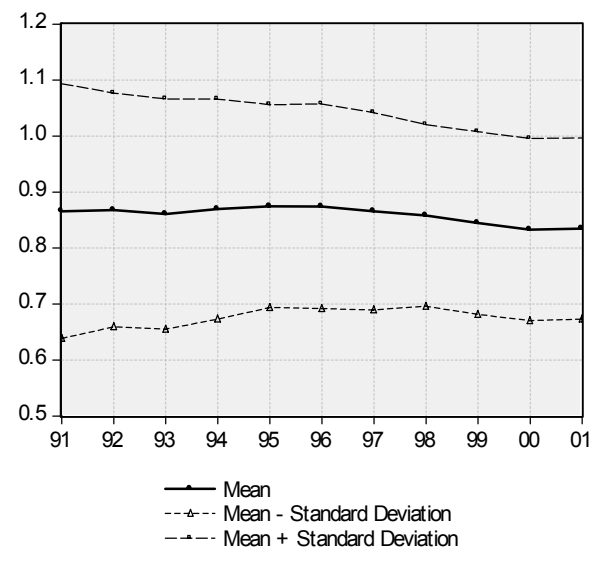

1.D

African Countries

Figure 1

Self-financing ratios, means and standard deviations. 


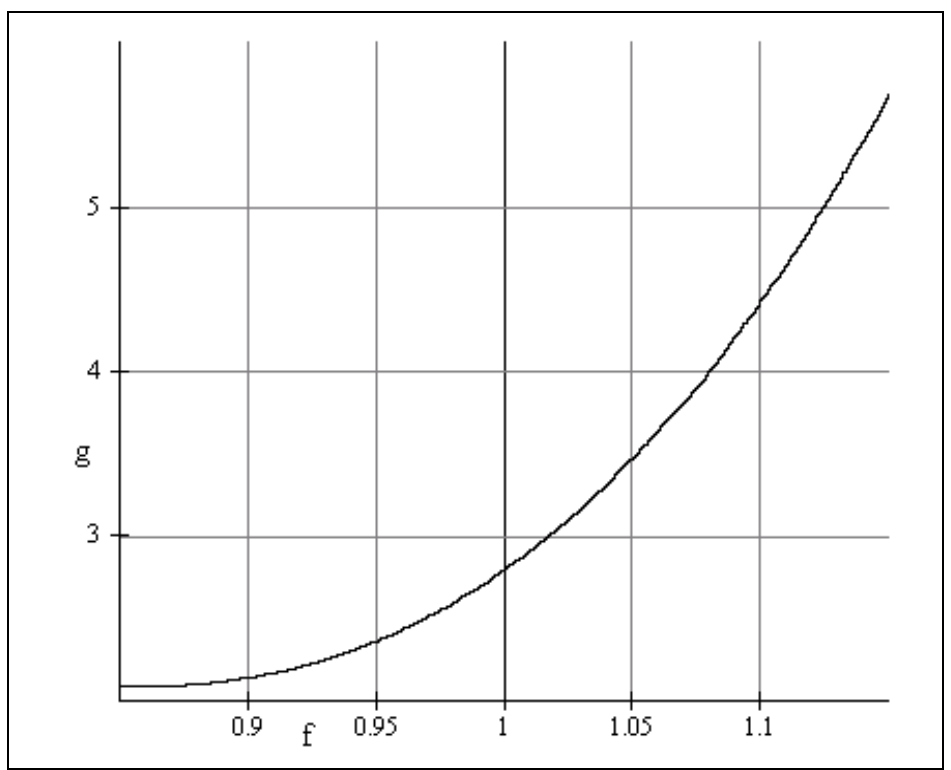

Figure 2

Growth and self-financing ratio, cross-country analysis, 1990s

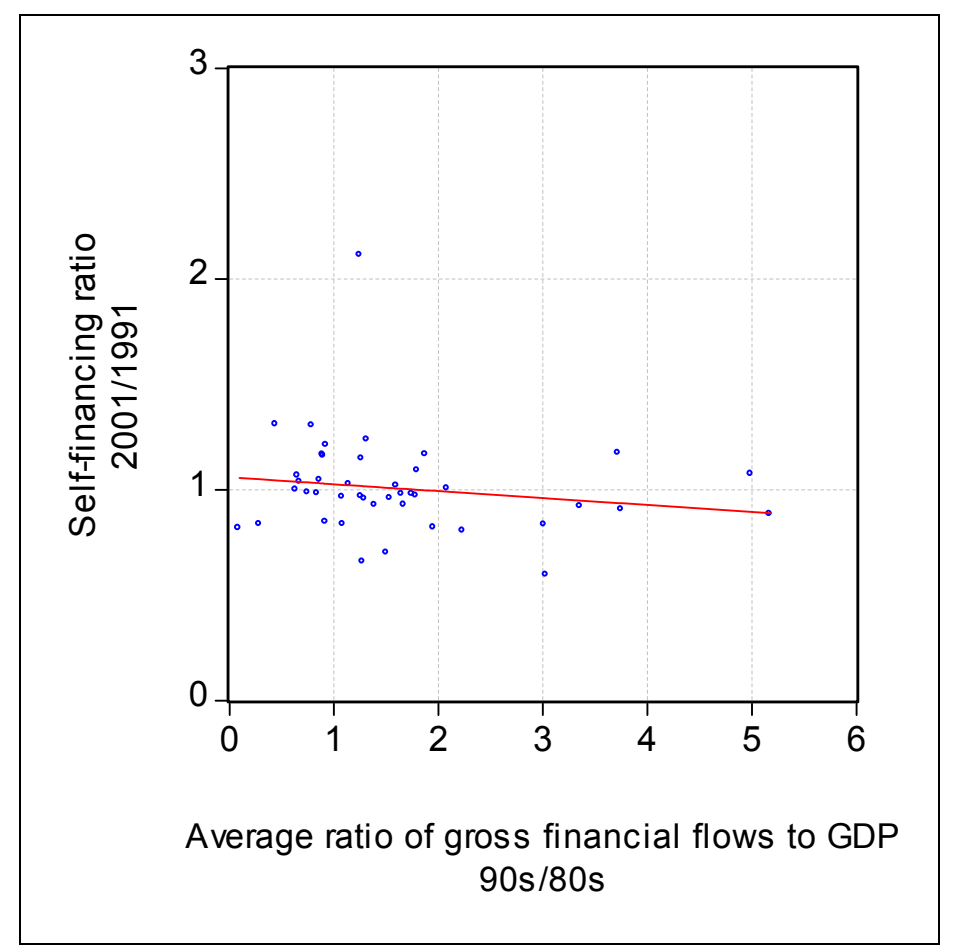

Figure 3

The association between deeper de-facto financial integration and changes in self-financing ratios 


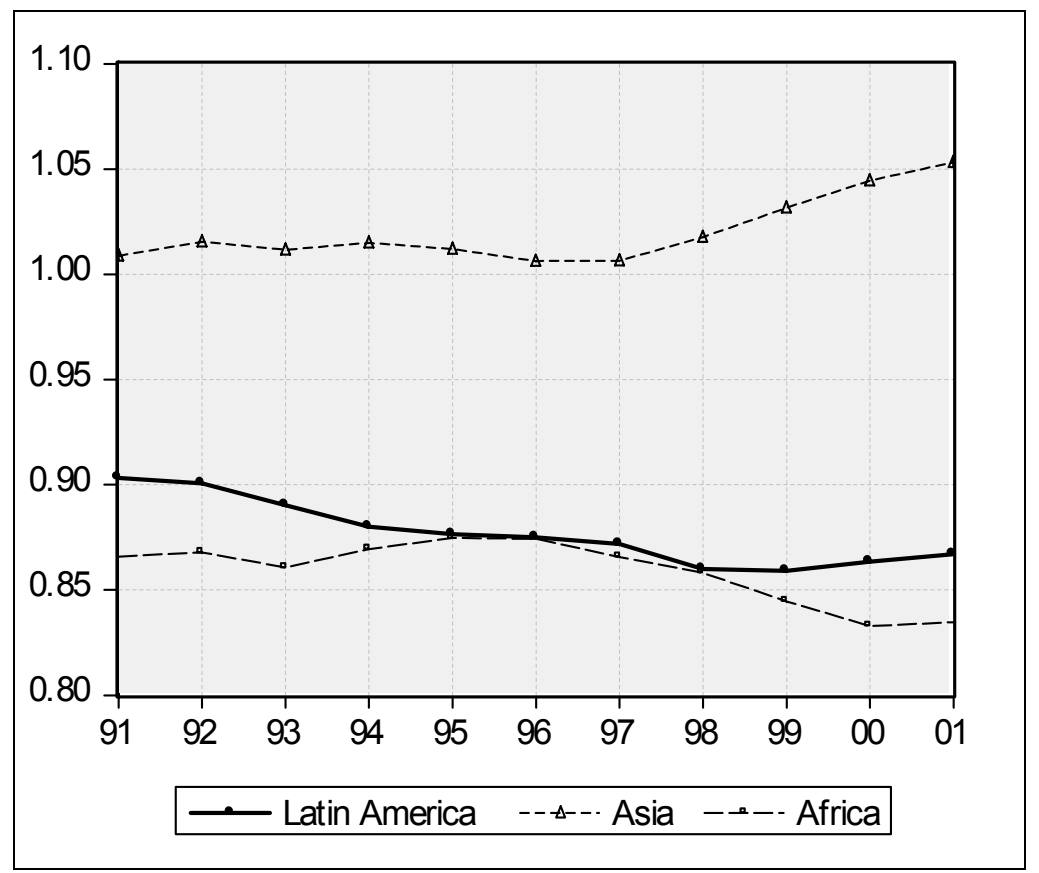

Figure 4

Self-financing ratio, means across regions

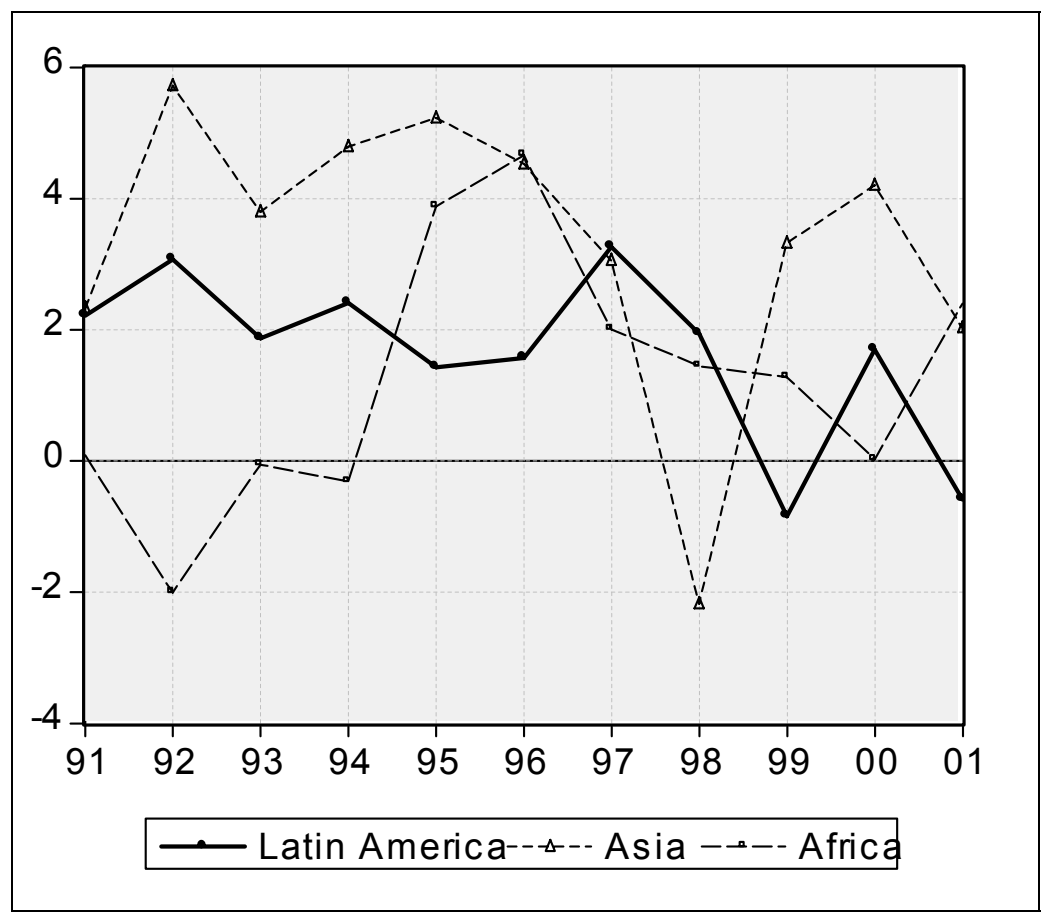

Figure 5

Annual GDP per capita growth, means across regions 


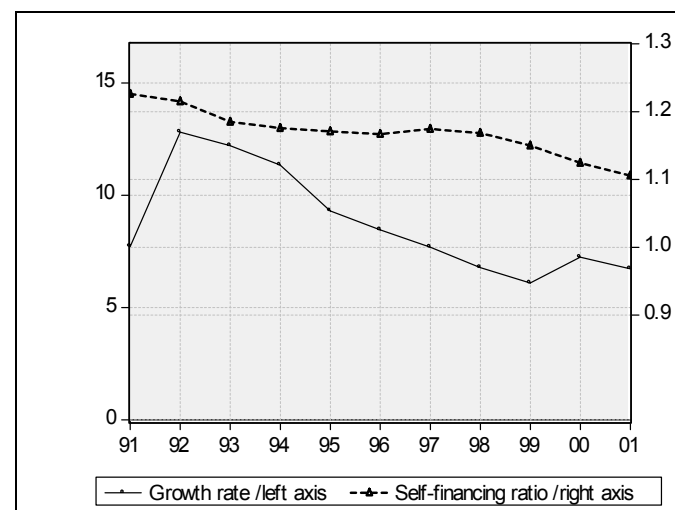

6.A

China

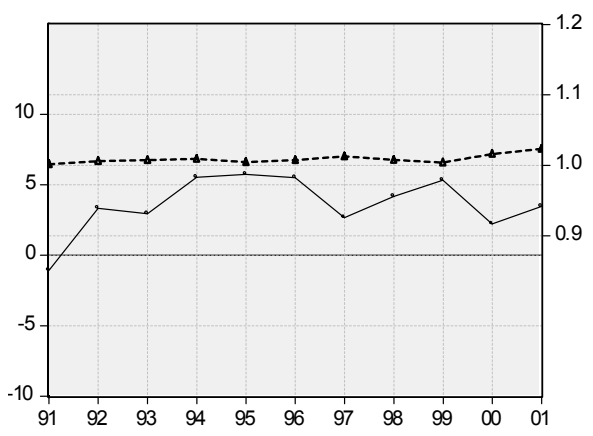

$\rightarrow$ Growth rate/left axis $\quad-\rightarrow$ - Self-financing ratio/right axis

6.C

India

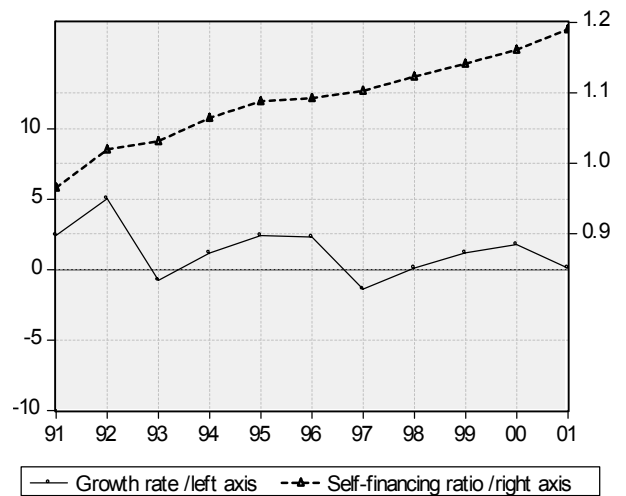

6.E

Pakistan

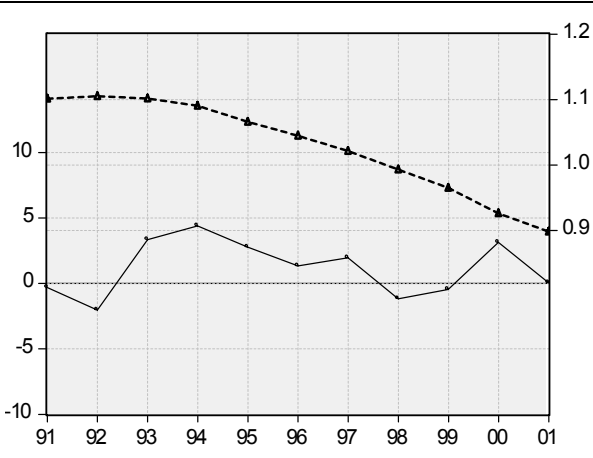

$\rightarrow$ Growth rate /left axis $\rightarrow-$ - Self-financing ratio/right axis

6.B

Brazil

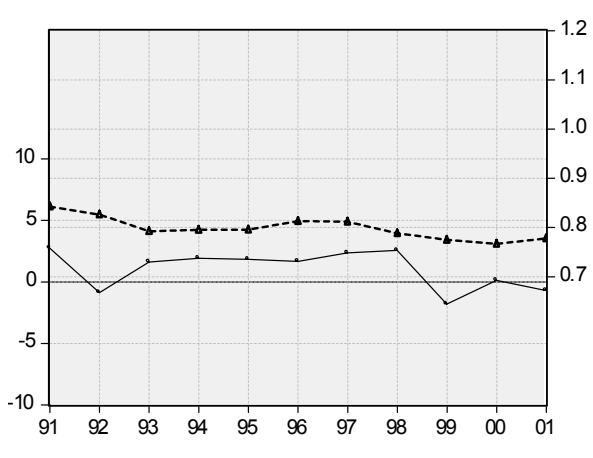

$\rightarrow$ Growth rate /left axis $\quad-\rightarrow$ - Seff-financing ratio/right axis

6.D

Bolivia

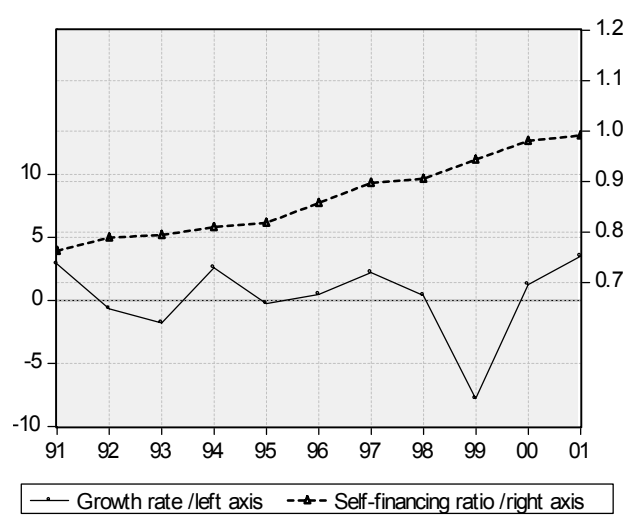

6.F

Ecuador

Figure 6

Self-financing ratios and GDP per capital growth rates in selected countries that did not experience major financial crisis 


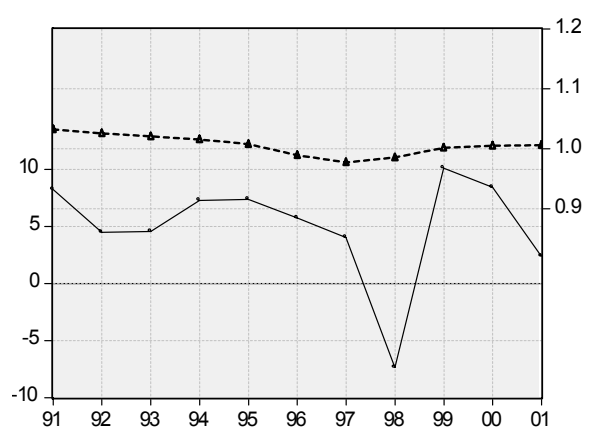

- Growth rate /left axis $\quad-\varangle-$ Seff-financing ratio /right axis

7.A

Korea

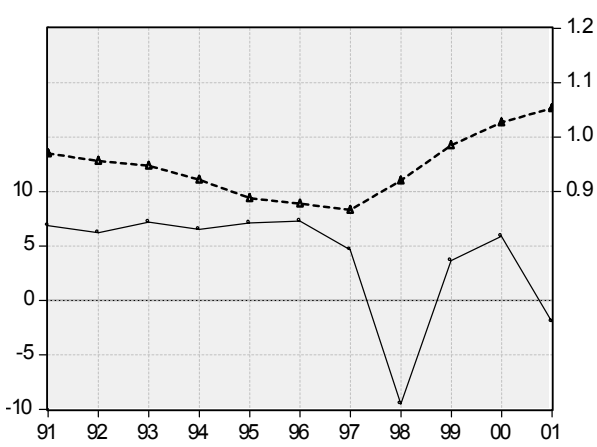

7.C

Malaysia

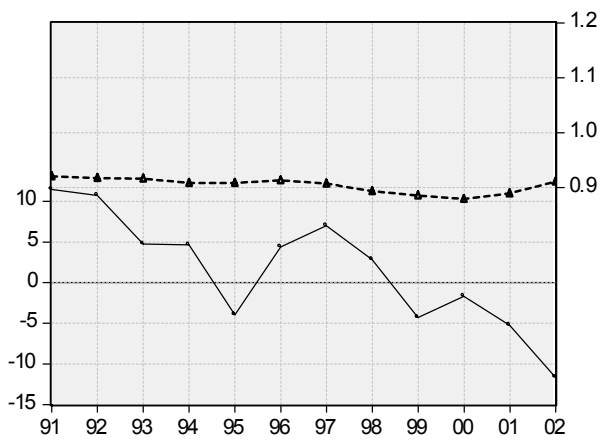

$\rightarrow$ Growth rate /left axis $-\infty$ - Self-financing ratio/right axis

7.E

Argentina

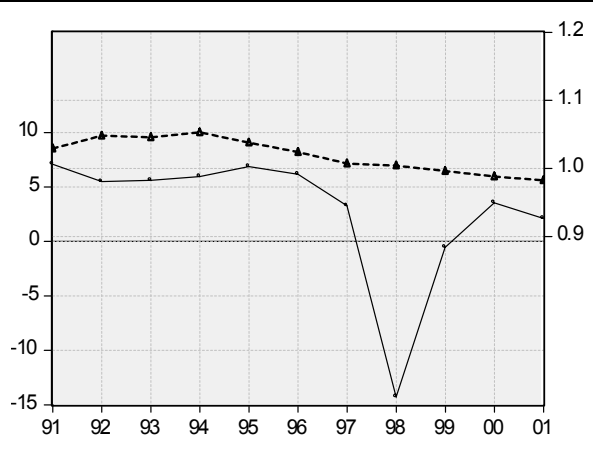

- Growth rate /left axis $-\rightarrow$ - Self-financing ratio /right axis

7.B

Indonesia

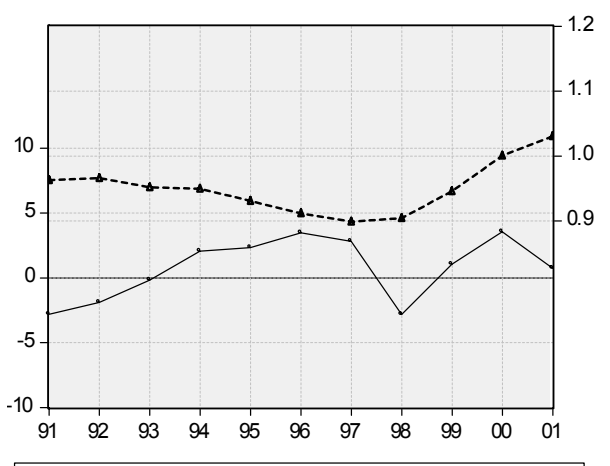

$\rightarrow$ Growth rate /left axis $\rightarrow-$ - Self-financing ratio/right axis

7.D

Philippines

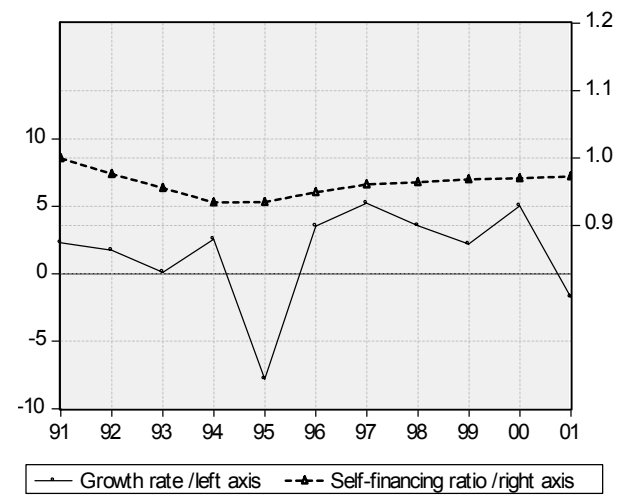

7.F

Mexico

Figure 7

Self-financing ratios and GDP per capital growth rates in selected countries that experienced major financial crisis 


\begin{tabular}{|c|c|c|c|}
\hline Dependent Variable: & Average per car & owth rate & e 90s \\
\hline & 1 & 2 & 3 \\
\hline Constant & -8.22 & -12.38 & -14.26 \\
\hline Mean self-financing & 11.00 & 11.78 & 12.88 \\
\hline & 3.19 & 3.54 & 3.75 \\
\hline$(\text { Mean self-financing })^{\wedge} 2$ & 48.38 & 68.56 & 88.90 \\
\hline & 2.47 & 3.28 & 3.86 \\
\hline$(\text { Mean self-financing })^{\wedge} 3$ & 42.36 & 66.88 & 91.76 \\
\hline & 1.87 & 2.69 & 3.27 \\
\hline Standard deviation of self-financing & & & \\
\hline ratio & -19.91 & -14.25 & -15.91 \\
\hline & -2.49 & -1.55 & -1.66 \\
\hline Institutional quality & & 0.69 & 0.76 \\
\hline & & 2.71 & 2.78 \\
\hline Trade openness & & & 0.01 \\
\hline & & & 1.22 \\
\hline Financial openness & & & -0.01 \\
\hline & & & -0.81 \\
\hline Observations & 47 & 41 & 39 \\
\hline R-squared & 0.28 & 0.42 & 0.49 \\
\hline Adjusted R-squared & 0.21 & 0.34 & 0.38 \\
\hline
\end{tabular}

Table 1

Explaining average per capita growth rates in the 90s. (t-statistics are presented in italics) 


\begin{tabular}{|c|c|c|c|c|}
\hline \multicolumn{2}{|c|}{ Dependent Variable: } & \multicolumn{3}{|c|}{$\begin{array}{l}\text { Standard deviation of self- } \\
\text { financing rate in the } 90 \mathrm{~s}\end{array}$} \\
\hline \multirow{5}{*}{$\begin{array}{l}\text { Constant } \\
\text { Institutional } \\
\text { Quality }\end{array}$} & 1 & 2 & 3 & 4 \\
\hline & 0.09 & 0.08 & 0.09 & 0.08 \\
\hline & & & & \\
\hline & -1.1 & -1.15 & -1.11 & -1.17 \\
\hline & -2.5 & -2.71 & -2.50 & -2.74 \\
\hline \multirow[t]{2}{*}{ Trade openness } & & 0.03 & & 0.03 \\
\hline & & 1.90 & & 2.01 \\
\hline \multirow{2}{*}{\multicolumn{2}{|c|}{ Financial openness }} & & 0.00 & -0.02 \\
\hline & & & -0.10 & -0.70 \\
\hline Observations & 39 & 39 & 39 & 39 \\
\hline \multirow{2}{*}{$\begin{array}{l}\text { R-squared } \\
\text { Adjusted R- } \\
\text { squared }\end{array}$} & 0.15 & 0.23 & 0.15 & 0.24 \\
\hline & 0.12 & 0.18 & 0.10 & 0.17 \\
\hline
\end{tabular}

Table 2

Explaining standard deviation of self-financing rates in the $90 \mathrm{~s}$. (t-statistics are presented in italics) 